\section{Why simple aesthetic dental treatment in general practice does not make all patients happy}

\author{
S. Sarin, ${ }^{1}$ D. Gilbert ${ }^{1}$ and K. Asimakopoulou ${ }^{* 2}$
}

VERIFIABLE CPD PAPER
IN BRIEF

- Illustrates psychological variables which may be predictors of how satisfied patients are with aesthetic dental treatment.

- Suggests dental practitioners might benefit from assessing a patient's psychological traits using simple selfreport tools.

- Explains why patient satisfaction with simple aesthetic dental treatment is not always what dentists might expect.

Objective We explored the role of personality and pre-treatment contentment with one's face and body in predicting satisfaction following simple aesthetic dental procedures. Methods In a single-centre repeated measures cohort design we examined the extent to which patient personality and baseline satisfaction with one's face and body predict post-treatment satisfaction. Data were collected from 60 patients attending a UK general practice in 2012. Adults ( $M$ age $=60.7 \pm 12.6$ years) receiving simple, routine aesthetic dental treatment participated. Satisfaction with one's face and body was assessed preand post-operatively through validated self-report measures. Results Although all participants were more satisfied posttreatment with their body overall $(t[59]=2.78, p<0.004)$ and with their face in particular ( $t 59]=1.83, p<0.035$ ), those scoring highly on neuroticism were generally unhappier both before and after treatment ( $r$ range $=0.277-0.360, p<0.05$ ). In multiple regressions, post-operative facial satisfaction $\left(R^{2}=0.475, p<0.001\right)$ was predicted by pre-operative facial satisfaction $(\beta=0.616, t=5.912, p<0.001)$ and to a lesser extent by neuroticism $(\beta=-0.241, t=2.248, p<0.001)$. Baseline happiness with one's body $(\beta=0.851, t=11.996, p<0.001)$ was the sole predictor of post-treatment body satisfaction $\left(R^{2}=0.744, p<0.001\right)$. Conclusions Psychological variables may be important predictors of satisfaction with dental treatment and the clinical benefits of assessing them pre-operatively should be explored.

\section{INTRODUCTION}

The provision of general dental care has seen a paradigm shift in recent years. ${ }^{1}$ This shift is due in part to new materials and bonding techniques but also due to the appetite of a discriminating public who now request an aesthetic result for all their treatment, be it a simple filling or denture replacing teeth in the aesthetic zone, through to more complex procedures requiring multiple indirect restorations. ${ }^{2}$

The dental motives for seeking aesthetic dental treatments may often seem obvious, for example, to correct a malocclusion or to ensure function and stability. However, less obvious reasons may explain a person seeking these treatments. These, often psychological, factors may include a person's self-perception of their appearance and social pressures..$^{3-5}$

The psychological profile of patients undergoing aesthetic dental procedures has

\footnotetext{
'Unit of Distance Learning, ${ }^{2}$ Unit of Social and Behavioural Sciences, King's College London, Guy's Hospital, London, SE1 9RW

*Correspondence to: Dr Koula Asimakopoulou

Email: koula.asimakopoulou@kcl.ac.uk
}

\section{Refereed Paper}

Accepted 17 April 2014

DOI: 10.1038/sj.bdj.2014.524

${ }^{\circledR}$ British Dental Journal 2014; 216: 681-685 been examined previously ${ }^{3,6-8}$ and has been linked to improvements in clinical practice in the area. For example, understanding a patient's psychological profile and motives for orthodontic treatment can improve clinician-patient communication and might be predictive of patient satisfaction. ${ }^{9}$

Patient satisfaction in dentistry has, of course, been explored previously ${ }^{10}$ and has value as a desirable objective in its own right, as an adjunct to patient compliance and finally as an indicator of quality of care. ${ }^{11}$ Research in dental patient satisfaction has focused mainly on orthognathic, denture and implant cases. ${ }^{6,12,13}$ Although some studies have examined several baseline factors that might impact post-treatment patient satisfaction, such as, how realistic patient expectations of treatment outcome were, ${ }^{14}$ and how interested the patient was in the first place in receiving treatment, ${ }^{12}$ patients' baseline satisfaction levels with specific aesthetic aspects of their face and body do not appear to have received attention. It would seem reasonable to suggest that people will have views about their face and overall appearance and that these views might lead them to come to the general dental practitioner's chair with different baseline levels of dissatisfaction with their dentition.
A factor related to satisfaction with one's overall appearance ${ }^{15}$ and potentially to how patients may react to aesthetic dental procedures is personality. ${ }^{16}$ The extent to which personality traits may predict patient satisfaction in dentistry has been examined extensively $^{17-20}$ and we now know that satisfaction with one's dentition ${ }^{19}$ and with one's smile ${ }^{18}$ can be reliably predicted by personality traits such as neuroticism. Neuroticism in this context refers to emotional stability, with people scoring high on neuroticism being considered as less emotionally stable, more reactive to stress, more prone to mood swings and generally more self-conscious than people scoring low on this trait.

Although personality traits may be predictive of satisfaction with dental procedures, work in this area has not considered the role that patients' pretreatment satisfaction levels with their overall appearance may play on their evaluation of outcome. It could be that although personality factors predispose one to be more or less happy with the way they look, ${ }^{15}$ their pre-treatment levels of satisfaction with their appearance are just as important. The significance of this idea for clinical practice lies in the fact that 
whereas personality is said to be fixed and stable, ${ }^{21}$ satisfaction with one's face and body is modifiable and an area that dental professionals can readily influence. It is known, for example, that where dental patients are exposed to 'ideal' facial images previously rated as highly attractive, their facial appearance satisfaction decreases. ${ }^{22}$ It follows then that should baseline satisfaction with one's appearance be a reliable predictor of post-treatment, then satisfaction pretreatment dental consultations need to focus on enhancing these malleable and open to intervention impressions of one's face and body as a precursor to subsequent, posttreatment satisfaction.

Much research in the areas of personality and satisfaction has used self-report questionnaires as a reliable tool to gain an insight into aspects of an individual's self perception. ${ }^{23}$ The Big Five Personality Test, based on the Big Five Personality Theory, measures the five fundamental dimensions of personality reliably ${ }^{24}$ while the Slade Body Index ${ }^{25}$ and simple Visual Analogue Scales have also been used in past research in the area reliably. ${ }^{26,27}$

On the basis of the above, this study examines the role of personality and pretreatment satisfaction with body and face in predicting post-aesthetic dental treatment satisfaction. The research questions addressed are:

1. Are patients' self-reported levels of satisfaction with facial appearance and with their body higher after aesthetic dental treatment?

2. Is there a relationship between personality factors, current and posttreatment satisfaction with aesthetic dental treatment?

3. How much variance in post-treatment satisfaction is predicted by personality and current satisfaction?

\section{METHODS}

\section{Ethical considerations}

The study adhered to the Helsinki protocol and approval was given by the King's College London Research Ethics Committee, (Reference number BDM/11/12-37).

\section{Participants}

Male and female participants over the age of 16 who could read and understand English were eligible to participate. They attended for the purposes of non-complex, aesthetic dental treatment at a multi-disciplinary General Dental Practice in South East England, UK between March-June 2012. Procedures included were vital and non-vital bleaching, direct or indirect restorations in a

Table 1 Demographic details, frequency of each procedure type carried out and number of previous aesthetic dental procedures an individual had undertaken

\begin{tabular}{l|l|l|l} 
& & Number & Percentage (\%) \\
\hline Gender & Male & 29 & 48.3 \\
& Female & 31 & 51.7 \\
\hline Procedure undertaken & Whitening & 5 & 8.3 \\
& Tooth-Coloured & 18 & 30 \\
& Restorations & 28 & 46.7 \\
& Crown and & 2 & 3.3 \\
& Bridge & 7 & 11.7 \\
& Veneers & & \\
\hline Number of previous aesthetic & Other & & 15 \\
dental procedures & 0 & 9 & 51.7 \\
& 1 & 31 & 23.3 \\
& 2 & 14 & 8.3 \\
& 3 & 5 & 1.7
\end{tabular}

Table 2 Descriptive statistics for satisfaction with facial appearance (VAS) and body satisfaction (BSS) pre- and post-treatment

\begin{tabular}{|l|l|l|l|l} 
& Mean (M) & $\begin{array}{l}95 \% \text { Confidence } \\
\text { intervals (Cls) }\end{array}$ & $\begin{array}{l}\text { Standard deviation } \\
\text { (SD) }\end{array}$ & $\begin{array}{l}\text { Standard error of } \\
\text { the mean }\end{array}$ \\
\hline Pre-treatment VAS & 70.86 & $65.46-76.26$ & 20.72 & 2.70 \\
\hline Post treatment VAS & 75.08 & $69.73-80.43$ & 20.55 & 2.68 \\
\hline Pre-treatment BSS & 38.61 & $34.76-42.45$ & 14.76 & 1.92 \\
\hline Post-treatment BSS & 35.86 & $32.32-39.40$ & 13.57 & 1.77 \\
\hline
\end{tabular}

tooth-coloured material that was visible and any form of denture in the aesthetic zone.

\section{Materials}

Participants completed the following measures:

\section{Demographic and treatment questionnaire}

This asked participants to report the aesthetic dental treatment to be undertaken, history of previous aesthetic dental treatment, sex and date of birth.

\section{The Big Five Personality Test ${ }^{24}$}

Developed by Buchannan et al., this online personality test is based on the big five model and consists of 41 questions derived from the international personality item pool. It is validated and well documented in the literature. ${ }^{24-28}$ The measure assesses the big five personality dimensions of extraversion, conscientiousness, neuroticism, agreeableness and openness. Each statement relates to the participant's perception of themselves. Participants were asked to indicate the strength of agreement with each statement using a scale from one (signifying strong agreement) to five (signifying strong disagreement) with two, three and four representing transitional responses. Participants were asked to respond as they felt at that moment in time and not how they wished to be in the future. They were also asked to answer as honestly as possible and in comparison to people of the same age and sex as themselves where relevant. The data collected from this questionnaire was imputed in to an online version http://www. utpsyc.org/Big5/. This software provided a numerical score for each of the five traits.

\section{The Body Satisfaction Scale (BSS)}

This reliable and valid ${ }^{25}$ scale has been previously used in dental settings. ${ }^{22}$ The BSS lists 16 body parts and participants indicate how satisfied they feel about each one by ticking a box from one (very satisfied) to seven (very dissatisfied). Higher scores in this measure indicate higher dissatisfaction with one's appearance.

\section{Visual Analogue Scale (VAS) - face satisfaction}

Participants marked how they felt about their face at that precise moment in time by marking on a $100 \mathrm{~mm}$ line ranging from 0 (not very happy) to 100 (very happy). Visual Analogue Scales commonly found in the literature are used to measure health outcomes and are sensitive enough to register changes before and after an intervention. ${ }^{26,27}$

\section{Procedure}

Patients were identified by one of the six dentists at the practice as being eligible. Once aesthetic dental treatment had been prescribed and consented for, patients were invited to participate in the study. A verbal explanation of the study was provided to potential respondents following their consultation appointment with the offer of 


\begin{tabular}{|c|c|c|c|c|c|c|c|c|c|}
\hline & Openness & Conscientiousness & Extraversion & Agreeableness & Neuroticism & $\begin{array}{l}\text { VAS } \\
\text { Pre- } \\
\text { treatment }\end{array}$ & \begin{tabular}{|l|} 
VAS \\
Post- \\
treatment
\end{tabular} & $\begin{array}{l}\text { BSS } \\
\text { Pre-treatment } \\
\text { satisfaction }\end{array}$ & $\begin{array}{l}\text { BSS } \\
\text { Post-treatment } \\
\text { satisfaction }\end{array}$ \\
\hline Openness Pearson's $r$ & 1 & -0.191 & $0.501^{* *}$ & 0.128 & -0.106 & 0.219 & .184 & -.091 & -0.086 \\
\hline Sig (2-tailed) & & 0.143 & 0.000 & 0.329 & 0.421 & 0.092 & 0.162 & 0.487 & 0.517 \\
\hline $\mathrm{N}$ & 60 & 60 & 60 & 60 & 60 & 60 & 59 & 60 & 59 \\
\hline $\begin{array}{l}\text { Conscientiousness } \\
\text { Pearson's } r\end{array}$ & -0.191 & 1 & -0.178 & 0.086 & 0.193 & -0.145 & $-0.285^{*}$ & $0.259^{*}$ & 0.188 \\
\hline Sig. (2-tailed) & 0.143 & & 0.174 & 0.512 & 0.139 & 0.270 & 0.029 & 0.045 & 0.154 \\
\hline $\mathrm{N}$ & 60 & 60 & 60 & 60 & 60 & 60 & 59 & 60 & 59 \\
\hline Extraversion Pearson's $r$ & $0.501^{* *}$ & -0.178 & 1 & 0.076 & -0.095 & 0.180 & 0.173 & 0.059 & 0.093 \\
\hline Sig. (2-tailed) & 0.000 & 0.174 & & 0.564 & 0.471 & 0.168 & 0.189 & 0.653 & 0.485 \\
\hline $\mathrm{N}$ & 60 & 60 & 60 & 60 & 60 & 60 & 59 & 60 & 59 \\
\hline $\begin{array}{l}\text { Agreeableness } \\
\text { Pearson's r }\end{array}$ & 0.128 & 0.086 & 0.076 & 1 & $-0.430^{* *}$ & 0.155 & 0.157 & -0.120 & -0.154 \\
\hline Sig. (2-tailed) & 0.329 & 0.512 & 0.564 & & 0.001 & 0.237 & 0.236 & 0.359 & 0.245 \\
\hline $\mathrm{N}$ & 60 & 60 & 60 & 60 & 60 & 60 & 59 & 60 & 59 \\
\hline Neuroticism Pearson's $r$ & -0.106 & 0.193 & -0.095 & $-0.430^{* *}$ & 1 & $-0.255^{*}$ & $-0.360^{* *}$ & $0.374^{* *}$ & $0.277^{*}$ \\
\hline Sig. (2-tailed) & 0.421 & 0.139 & 0.471 & 0.001 & & 0.049 & 0.005 & 0.003 & 0.033 \\
\hline $\mathrm{N}$ & 60 & 60 & 60 & 60 & 60 & 60 & 59 & 60 & 59 \\
\hline $\begin{array}{l}\text { VAS_pre-treatment } \\
\text { Pearson's r }\end{array}$ & 0.219 & -0.145 & 0.180 & 0.155 & $-0.255^{*}$ & 1 & $0.632^{* *}$ & $-0.647^{* *}$ & $-0.638^{* *}$ \\
\hline Sig. (2-tailed) & 0.092 & 0.270 & 0.168 & 0.237 & 0.049 & & 0.000 & 0.000 & 0.000 \\
\hline $\mathrm{N}$ & 60 & 60 & 60 & 60 & 60 & 60 & 59 & 60 & 59 \\
\hline $\begin{array}{l}\text { VAS_post-treatment } \\
\text { Pearson's } r\end{array}$ & 0.184 & $-0.285^{*}$ & 0.173 & 0.157 & $-0.360^{* *}$ & $0.632^{* *}$ & 1 & $-0.590^{* *}$ & $-0.683^{* *}$ \\
\hline Sig. (2-tailed) & 0.162 & 0.029 & 0.189 & 0.236 & 0.005 & 0.000 & & 0.000 & 0.000 \\
\hline $\mathrm{N}$ & 59 & 59 & 59 & 59 & 59 & 59 & 59 & 59 & 59 \\
\hline $\begin{array}{l}\text { BSS pre-treatment } \\
\text { Pearson's } r\end{array}$ & -0.091 & $0.259^{*}$ & 0.059 & -0.120 & $0.374^{* *}$ & $-0.647^{* *}$ & $-0.590^{* *}$ & 1 & $0.860^{* *}$ \\
\hline Sig. (2-tailed) & 0.487 & 0.045 & 0.653 & 0.359 & 0.003 & 0.000 & 0.000 & & 0.000 \\
\hline $\mathrm{N}$ & 60 & 60 & 60 & 60 & 60 & 60 & 59 & 60 & 59 \\
\hline $\begin{array}{l}\text { BSS post-treatment } \\
\text { Pearson's } r\end{array}$ & -0.086 & 0.188 & 0.093 & -0.154 & $0.277^{*}$ & $-0.638^{* *}$ & $-0.683^{* *}$ & $0.860^{* *}$ & 1 \\
\hline Sig. (2-tailed) & 0.517 & 0.154 & 0.485 & 0.245 & 0.033 & 0.000 & 0.000 & 0.000 & \\
\hline $\mathrm{N}$ & 59 & 59 & 59 & 59 & 59 & 59 & 59 & 59 & 59 \\
\hline
\end{tabular}

a follow up explanatory telephone call from the researcher. Reassurance that treatment provision and future care would be unaffected by their decision to participate was given and the anonymous and confidential data collection process was emphasised. The patient information sheet and the series of questionnaires were provided at this point. Participants were asked to either complete the pre-operative questionnaires at home on the day of their treatment appointment or attend 10 minutes early for their appointment and complete them in the practice waiting room. Completion of forms was taken as consent of participation. The anonymised completed pre-operative questionnaires were handed in to reception and placed in a secure filing cabinet. Upon completion of treatment, participants filled in the post-treatment questionnaires in the practice waiting area.

\section{RESULTS}

\section{Demographics}

Eighty-six participants were approached to take part in the study and all agreed to take away the measures and consider participation. Twenty-three failed to fill in the pre-treatment questionnaire, 63 completed pre-treatment measures and 3 forms were lost to follow up due to incomplete completion. Final analysis used data from 60 people.

The final sample consisted of older adults (M age $60.7 \pm 12.6$ years) and was balanced in gender ( $n=29 / 31$ males/females). See Table 1 for the sample demographic and previous aesthetic dental procedure profile.

Research question one: are patients' self-reported levels of satisfaction with facial appearance and with their body higher after aesthetic dental treatment?

In order to determine if post-treatment satisfaction was higher after the clinical 
dental procedure than at baseline, we evaluated satisfaction with one's face (VAS) and body (BSS) pre-and post-aesthetic dental treatment. Descriptive statistics for pre- and post-treatment scores for facial appearance as measured by a 0-100 Visual Analogue Scale (VAS) and Body Satisfaction (BSS) are shown in Table 2.

Of the 60 people providing data, 31 had higher scores post-treatment on this scale, 17 had lower scores and 12 participants remained the same. In inferential testing, the overall sample satisfaction with their face as measured by VAS significantly increased post-treatment (paired t [59] $=1.83, \mathrm{p}<0.035$ )

In terms of body satisfaction as assessed by the BSS, of the 60 people providing data, 38 were more satisfied post-treatment than they were pre-treatment, three were less satisfied than at baseline and nine participants showed the same body satisfaction after treatment as at baseline. Overall, BSS scores post-treatment decreased, indicating a statistically significant increase in overall satisfaction with one's body (paired t [59] $=2.78, \mathrm{p}<0.004,1$-tailed).

\section{Research question two: is there a relationship between personality factors, current and post-treatment satisfaction with aesthetic dental treatment?}

Pearson's correlation coefficients were calculated for personality variables and pre- and post-treatment VAS and BSS scores. Higher scores on the personality variables show a higher degree of that particular personality trait. Higher VAS scores show greater satisfaction with facial appearance. Higher BSS scores show higher dissatisfaction with various parts of the body (Table 3).

The only personality trait positively correlating with satisfaction (VAS and BSS) was neuroticism. Neuroticism was negatively related with both pre- $(r=-0.255, p=0.049)$ and post-treatment satisfaction with one's face $(r=-0.360, p=0.005)$. Neuroticism was also related reliably with pre$(\mathrm{r}=0.374, \mathrm{p}=0.003)$ and post-treatment body satisfaction scores as measured by the BSS ( $r=0.277, p=0.033)$. Overall, higher neuroticism was related to more discontentment with face and body both pre- and post-operatively.

\section{Research question three: how much variance in post-treatment satisfaction is predicted by personality and current satisfaction?}

Two linear regressions were run. Demographic factors (age, sex) and number of previous aesthetic dental procedures were hierarchically entered into step one, while the five personality traits and i) pretreatment facial appearance satisfaction (VAS) (regression one) or ii) pre-treatment body satisfaction (BSS) (regression two) were entered in step two, using a stepwise model.

\section{Satisfaction with facial appearance (VAS)}

Demographics and previous treatment history explained negligible $\left(\mathrm{R}^{2}=0.053\right)$, non-significant $(\mathrm{F}[3,58]=1.028, \mathrm{p}>0.05)$ amounts of variance in post treatment VAS. A moderate $\left(R^{2}=0.475\right)$, statistically significant $(\mathrm{F}[4,58]=9.598, \mathrm{p}<0.001]$ amount of variance in post-treatment VAS, however, was explained by pre-treatment VAS $(\beta=0.616$, $\mathrm{t}=5.912, \mathrm{p}<0.001]$ and to a lesser extent neuroticism ( $\beta=-0.241, \mathrm{t}=2.248, \mathrm{p}<0.001]$.

Primarily pre-treatment satisfaction with one's face and to a lesser extent neuroticism, predicted post-treatment satisfaction with facial appearance. Interestingly, no other personality trait tested predicted posttreatment facial satisfaction.

\section{Body Satisfaction (BSS)}

Demographics and previous treatment profile explained tiny $\left(\mathrm{R}^{2}=0.079\right)$ non-significant $(\mathrm{F}[3,58]=2.656, \mathrm{p}>0.05)$ amounts of variance in post treatment BSS. A substantial $\left(R^{2}=0.744\right)$, statistically significant $(\mathrm{F}[4,5]=43.144, \mathrm{p}<0.001)$ amount of variance in post-treatment body satisfaction (as assessed by the BSS), however, was explained by pre-treatment body satisfaction BSS $(\beta=0.851, t=11.996, p<0.001)$. Not a single personality trait was successful in predicting post-operative body satisfaction.

All analyses were completed using SPSS v.18.

\section{DISCUSSION}

The study has shown that, as expected, following simple aesthetic dental treatment patients were generally more satisfied with their face but also with their body overall, than before treatment. A significant correlation between neuroticism and general satisfaction with face and body was seen where those high in neuroticism were generally unhappier with their appearance both before and after treatment. No other personality trait measured by the big five model correlated with either facial satisfaction (VAS) or general body satisfaction (BSS). In predicting post-treatment satisfaction, multiple linear regression analyses confirmed that the individual's preoperative facial satisfaction profile and to a lesser extent neuroticism, were predictive of post-operative facial satisfaction. In terms of overall body satisfaction, the only reliable predictor post-operatively was the patients' pre-operative body satisfaction. So, the more content patients were generally with their body pre-treatment the more satisfied they seemed after treatment irrespective of personality.

Our findings extend previously published dental practice studies finding negative associations between neuroticism and patient satisfaction. ${ }^{6,17,28,29}$ The current findings further echo work ${ }^{20}$ that found that pre-operative low appearance evaluation and body dissatisfaction were risk factors for post-operative dissatisfaction in a study on patients undergoing cosmetic facial surgery and dentistry. It is of interest, however, that neither neuroticism nor any other personality variable measured in this study succeeded in predicting post treatment satisfaction with one's body. It could be that people who opt to take up aesthetic dental work are people who are generally happy about the way they look overall, with the only concern being that of dental appearance.

It is also of interest and of significant practical clinical use to see that pretreatment satisfaction with one's face and body is a reliable predictor of post-treatment satisfaction. Unlike personality traits that are resistant to change, satisfaction with one's appearance is malleable. ${ }^{22}$ As such, it would be useful to spend time assessing patients' satisfaction with their appearance preoperatively and ensuring that a patient is as clear about the positive (rather than those needing attention), aspects of their facial appearance as possible, before engaging in dental treatment. Our data suggest that, contrary to what may be happening in current clinical practice, it would be in the dentist's and patient's interest to ensure that patients start from as high a level of pre-treatment satisfaction as is practically possible, rather than focusing on the source of discontentment with their dentition. To this end, interventions to enhance body and face satisfaction in the short term that could be used in general dental practice should be evaluated in future work.

The current findings should, of course, be interpreted within the context of the study's limitations. Although our sample size was large enough for the purpose of the analyses we undertook, these findings should be replicated with a larger, demographically varied sample and with a variety of dentists. Analyses looking at the possible relationship between the dentist providing the treatment and post-treatment satisfaction, as well as the relationship between previous treatment satisfaction and current treatment provided, may prove useful further research avenues. Our sample was somewhat older than one may expect, a finding that is perhaps 
reflective of those currently able to afford aesthetic dental treatment in the UK on a private basis. Future research in this area should determine the demographics of a typical patient receiving aesthetic dental treatment. There was no consideration of ethnicity, religious or cultural beliefs, nor were complex aesthetic procedures studied, all of which may influence satisfaction. Levels of dental anxiety at various stages of the procedure were not measured. As is the norm with studies in this field we did not follow up patients longitudinally to explore whether their body and face satisfaction levels remained long-term. Outcome satisfaction in this study was measured using the parameters of the face and overall body, which are only two of the numerous factors that predict satisfaction. ${ }^{10}$ The regression analyses we undertook show that a lot of variance in satisfaction post treatment can be explained by pre-treatment satisfaction levels and to a lesser extent neuroticism, but, obviously they do not imply any causative relationship between predictors and outcomes.

Aesthetic dental work undertaken in general practice is unusual in that not only does it include treatments undertaken for clinical necessity but also where no underlying disease process exists. These two differing patient groups may yield differing baseline satisfaction levels, which should be confirmed by further research.

Overall, the current study indicates the important role that patient beliefs about their face and body may have in predicting satisfaction with aesthetic dental procedures undertaken in general practice. General dental practitioners may benefit by considering and assessing these psychological variables before treating patients in pursuit of the perfect smile.

1. Theobald A H, Wong B K, Quick A N, Thomson $W M$. The impact of the popular media on cosmetic dentistry. NZ Dent J 2006; 102: 58-63.

2. Terry D A, Geller W. Esthetic and restorative dentistry: material selection and technique. Hanover Park, IL: Quintessence Publishing, 2013.

3. Somani A, Newton J T, Dunne S, Gilbert D B. The impact of visible dental decay on social judgements: comparison of the effects of location and extent of lesion. Int Dent J 2010; 60: 169-174.

4. Karunakaran T, Gilbert D, Asimakopoulou K, Newton T. The influence of visible dental caries on social judgements and overall facial attractiveness among undergraduates. J Dent 2011: 39: 212-217.

5. Ahmad I. Risk management in clinical practice. Part 5. Ethical considerations for dental enhancement procedures. Br Dent J 2010; 209: 207-214.

6. Finlay P M, Atkinson J M, Moos K F. Orthognathic surgery: patient expectations; psychological profile and satisfaction with outcome. Br J Oral Maxillofac Surg 1995; 33: 9-14.

7. Davis L G, Ashworth P D, Spriggs L S. Psychological effects of aesthetic dental treatment. J Dent 1998; 26: $547-554$.

8. Williams D M, Bentley R, Cobourne M T et al. Psychological characteristics of women who require orthognathic surgery: comparison with untreated controls. Br J Oral Maxillofac Surg 2009; 47: 191-195.

9. Pabari S, Moles D R, Cunningham S J. Assessment of motivation and psychological characteristics of adult orthodontic patients. Am J Orthod Dentofacial Orthop 2011: 140: e263-272.

10. Newsome P R, Wright GH. A review of patient satisfaction: 2. Dental patient satisfaction: an appraisal of recent literature. Br Dent J 1999: 186: 166-170.

11. Clark S C, Asimakopoulou K. Patient Satisfaction following treatment with intravenous sedation. Social Science and Dentistry 2012; 2: 10-14.

12. Chen $B$, Zhang $Z K$, Wang $X$. Factors influencing postoperative satisfaction of orthognathic surgery patients. Int J Adult Orthodon Orthognath Surg 2002; 17: 217-222.

13. Papaspyridakos $P$, Chen $C J$, Singh $M$, Weber $H P$, Gallucci G O. Success criteria in implant dentistry: a systematic review. J Dent Res 2012; 91: 242-248.

14. Bellini D, Dos Santos M B, De Paula Prisco Da Cunha $\checkmark$, Marchini L. Patients' expectations and satisfaction of complete denture therapy and correlation with locus of control. J Oral Rehabil 2009; 36: 682-686.

15. Kvalem I L, von Soest T, Roald H E, Skolleborg K C. The interplay of personality and negative comments about appearance in predicting body image. Body Image 2006; 3: 263-273.

16. McCrae R R, Costa P J Jr. Personality trait structure as a human universal. Am Psychol 1997; 52: 509-516.

17. Al-Omiri M K, Lamey P J, Cooper C, Clifford T. Relationship between personality and satisfaction with the dentition in tooth wear patients. Eur J Prosthodont Restor Dent 2006; 14: 179-184.

18. Van der Geld P, Oosterveld P, Van Heck G, KuijpersJagtman A M. Smile attractiveness. Self-perception and influence on personality. Angle Orthod 2007; 77: 759-765.

19. Karasneh J, Al-Omiri M K, Al-Hamad K Q, Al Quran FA. Relationship between patients' oral healthrelated quality of life, satisfaction with dentition, and personality profiles. J Contemp Dent Pract 2009; 10: E049-056.

20. Honigman R J, Jackson A C, Dowling N A. The PreFACE: a preoperative psychosocial screen for elective facial cosmetic surgery and cosmetic dentistry patients. Ann Plast Surg 2011; 66: 16-23.

21. Soldz S, Vaillant G E. The big five personality traits and the life course: a 45-year longitudinal study. J Res Pers 1999; 33: 208-232.

22. Newton J T, Minhas G. Exposure to 'ideal' facial images reduces facial satisfaction: an experimental study. Community Dent Oral Epidemiol 2005; 33: $410-418$.

23. McDonald J. Measuring personality constructs: The advantages and disadvantages of self-reports, informant reports and behavioural assessments. Enquire 2008; 1: 1.

24. Buchanan $T$, Johnson J, Goldberg L. Implementing a five-factor personality inventory for use on the Internet. Eur J Psychol Assess 2005; 21: 115-127.

25. Slade P D, Dewey M E, Newton T, Brodie D, Kiemle G. Development and preliminary validation of the Body Satisfaction Scale (BSS). Psychology and Health 1990; 4: 213-220.

26. McCormack H M, Horne D J, Sheather S. Clinical applications of visual analogue scales: a critical review. Psychol Med 1988; 18: 1007-1019.

27. Torrance G W, Feeny D, Furlong W. Visual analogue scales: do they have a role in the measurement of preferences for health states? Med Decis Making $2001 ; 21: 329-334$.

28. Critchlow S B, Ellis J S. Prognostic indicators for conventional complete denture therapy: a review of the literature. J Dent 2010; 38: 2-9.

29. Kiyak H A, McNeill R W, West R A, Hohl T, Heaton $P$ J. Personality characteristics as predictors and sequelae of surgical and conventional orthodontics. Am J Orthod 1986; 89: 383-392. 